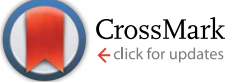

Cite this: RSC Adv., 2016, 6, 36723

Received 29th February 2016

Accepted 5th April 2016

DOI: 10.1039/c6ra05341f

\section{One "Click" access to self-complementary molecular modules for halogen bonding $\dagger$}

\author{
G. Cavallo, ${ }^{\star a}$ P. Metrangolo, ${ }^{\text {ab }}$ T. Pilati, ${ }^{a}$ G. Resnati, ${ }^{a}$ A. Scrivanti, ${ }^{c}$ M. Aversa ${ }^{d}$ \\ and E. Cariati
}

www.rsc.org/advances

Novel $D-\pi-A$ push-pull chromophores were synthesized in good yields by CuAAc coupling of 4-X-2,3,5,6-tetrafluorophenyl-1-azides $(\mathrm{X}=\mathrm{H}, \mathrm{Br}, \mathrm{I})$ with 4-ethynyl-dimethylaniline. Thanks to the selfcomplementary binding sites at the molecular ends, the iodo derivative self-organizes in the solid state forming head-to-tail halogenbonded one-dimensional unlimited chains. The second-order NLO properties of the iodo compound have been investigated by the solution-phase electric field induced second-harmonic generation method (EFISH).

Over the past few years halogen bonding (XB) has quickly grown from a scientific curiosity to a key structural element in directing and controlling molecular self-assembly phenomena. ${ }^{1-3}$ First recognized as an effective tool in crystal engineering, ${ }^{4,5}$ the application of $\mathrm{XB}$ is nowadays moving towards a wide range of fields encompassing organocatalysis, ${ }^{6}$ biology and drug design, ${ }^{7-10}$ anion transport and recognition, ${ }^{11-15}$ and materials science. ${ }^{16-23}$ According to the IUPAC definition, ${ }^{24} \mathrm{XB}$ is an attractive non-covalent interaction occurring between an electrophilic halogen atom in a molecule and a nucleophile. The ability of halogen atoms to act as electrophiles relies on the anisotropic distribution of the electron density around halogen atoms involved in covalent bonds with one or more atoms: ${ }^{25}$ a cap of positive electrostatic potential (the so-called $\sigma$-hole ${ }^{26}$ ) is generated on the elongation of each covalent bond, and is responsible for the interaction with

${ }^{a}$ NFMLab, Department of Chemistry, Materials, and Chemical Engineering "Giulio Natta”, Politecnico di Milano, Via L. Mancinelli 7, 20131 Milan, Italy. E-mail: gabriella.cavallo@polimi.it

${ }^{b}$ VTT-Technical Research Centre of Finland, Biologinkuja 7, 02150 Espoo, Finland 'Dipartimento DSMN, Università Ca'Foscari Venezia, Via Torino 15, I-30172 Mestre, Italy

${ }^{d}$ Consorzio Interuniversitario CIRCC, Via Ulpiani 27, I-70126 Bari, Italy

${ }^{e}$ Dipartimento di Chimica and INSTM UdR Milano, University of Milan, via Golgi 19, I20133 Milan, Italy

$\dagger$ Electronic supplementary information (ESI) available: Synthetic procedures, NMR spectra, CIF, and X-ray data. CCDC 1453398. For ESI and crystallographic data in CIF or other electronic format see DOI: 10.1039/c6ra05341f nucleophiles. The strength and directionality of XB depend on both the magnitude and size of the $\sigma$-hole and can be easily tuned by modifying the electron-withdrawing ability of substituents in the vicinity of the halogen. ${ }^{27}$

Haloperfluoroalkanes ${ }^{28,29}$ and haloperfluoroarenes ${ }^{30-32}$ have been largely applied as XB donors, since they form particularly short and directional interactions, thus allowing structural control over the final supramolecular aggregates. While the synthesis of haloperfluoroalkanes is not trivial, haloperfluoroarenes moieties have been easily appended to a wide diversity of organic compounds through nucleophilic aromatic substitution $\left(\mathrm{S}_{\mathrm{N}} \mathrm{Ar}\right) .^{33,34}$ In fact, the presence of strong electronwithdrawing substituents such as fluorine atoms, makes possible the nucleophilic substitution on aromatic rings, affording to new carbon-carbon or carbon-heteroatom bonds via the selective $\mathrm{C}-\mathrm{F}$ bond cleavage. ${ }^{35}$ The nucleophilic aromatic substitution $\left(\mathrm{S}_{\mathrm{N}} \mathrm{Ar}\right)$ has been previously applied for the preparation of ditopic halogen-bonded donors, ${ }^{33}$ and has proven to be an effective strategy to new tectons for XB-driven selfassembly. ${ }^{34,36}$

In order to broaden the panel of accessible XB-donors, additional synthetic strategies are required for introducing halo-perfluorinated moieties on different molecular scaffolds, characterized by new electronic and structural properties. Hopefully these new synthetic methodologies should be chemoselective, utilize mild reaction conditions and result in high yields. According to Sharpless ${ }^{37}$ the concept of click chemistry applies to reactions that are wide in scope, chemo- and stereoselective and highly efficient. Click reactions proceed smoothly under mild conditions, and the products are recovered in high yield with a minimum purification effort. Among the reactions fulfilling these criteria, the Cu-catalyzed azide-alkyne cycloaddition (CuAAC) ${ }^{\mathbf{3 8 - 4 0}}$ has gained paramount importance. This reaction is in fact well suited to link together molecular building blocks and, accordingly, has found widespread application in the synthesis of dendrimeric structures. ${ }^{\mathbf{4 1 - 4 7}}$ By contrast there are only few examples in which 1,2,3-triazoles prepared via CuAAC reaction have been used as $\pi$-conjugated linker in 
donor- $\pi$-acceptor (D- $\pi-\mathrm{A})$ chromophores. ${ }^{48-53}$ These $\mathrm{D}-\pi-\mathrm{A}$ push-pull molecules, in which $\mathrm{D}$ is an electron-donating group and $\mathrm{A}$ is an acceptor moiety, constitute an important class of compounds capable of second-order nonlinear optical (NLO) activities ${ }^{54-56}$ which are interesting for application in the electrooptical devices field.

The aim of the present study was to employ the CuAAC click chemistry in the synthesis of self-complementary molecular modules for halogen bonding. Specifically, we were intrigued to use the triazole-forming click reaction to link an aromatic XB-donor terminus, to a dimethylamine substituted aryl moiety acting as XB-acceptor (see Scheme 1). In the coupling product the triazole ring behaves as a $\pi$ bridge linking a donor group to an acceptor one, resulting in novel D- $\pi-\mathrm{A}$ push-pull chromophores.

The presence of electron withdrawing substituents (EWS) on aryl moieties makes azides $\mathbf{1 a}-\mathbf{c}^{\mathbf{4 5}}$ particularly challenging substrates ${ }^{46-48}$ however we found that they can be quite efficiently coupled with $N, N$-dimethylbenzenamine by employing the most usual $\mathrm{CuSO}_{4} \cdot 5 \mathrm{H}_{2} \mathrm{O} / \mathrm{Na}$-ascorbate catalytic system. The sought 1,4-disubstituted 1,2,3-triazoles were obtained in moderately good yields (50-60\%). Enhanced yields (up to 80\%) in 2c were obtained when the coupling was carried out by employing CuI as catalyst according to Recsei's methodology. ${ }^{57}$ While the present work was in progress Zhang and co-workers reported $^{58}$ the synthesis of 1-polyfluoroaryl-1,2,3-triazoles via a copper-catalysed one-pot three-component reaction of polyfluoroarenes, sodium azide, and terminal alkynes. They found that the optimal conditions include the use of $\mathrm{Cu}(\mathrm{OAc})_{2} \cdot \mathrm{H}_{2} \mathrm{O}$ as the catalyst and $\mathrm{CH}_{3} \mathrm{CN}$ as solvent while other $\mathrm{Cu}$ sources used with the association of sodium ascorbate as the reducing agent were ineffective affording only to trace amounts of the desired products.

2a-c were characterized by ${ }^{1} \mathrm{H},{ }^{13} \mathrm{C}$ and ${ }^{19} \mathrm{~F}$ NMR spectroscopy, UV-vis spectroscopy GC-MS and elemental analysis. Formation of the sought push-pull molecules is apparent from the presence in the ${ }^{1} \mathrm{H}$ NMR spectra of $2 \mathbf{a}-\mathbf{c}$ of a triplet $\left({ }^{4} J_{\mathrm{H}-\mathrm{F}}=\right.$

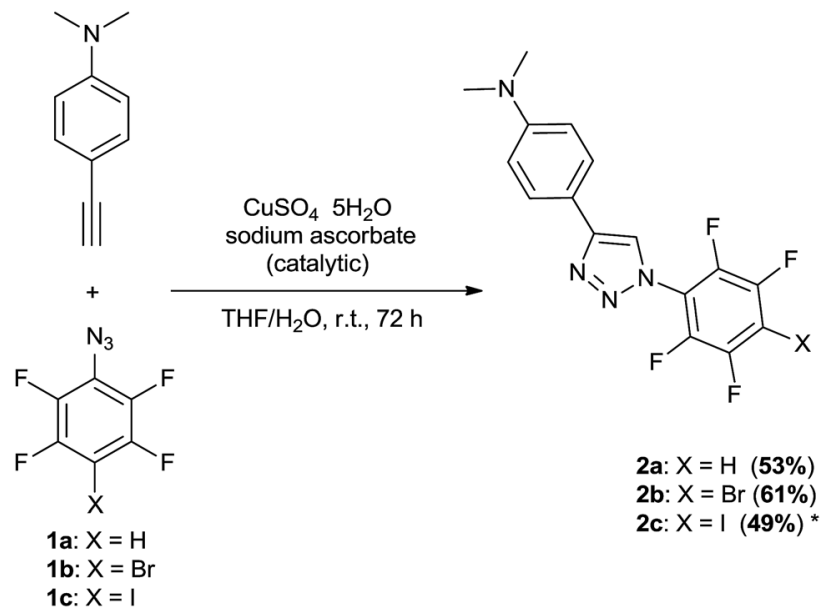

Scheme 1 Synthesis of the novel D- $\pi$-A push-pull molecules via $\mathrm{Cu}$ catalyzed azide-alkyne cycloaddition (CuAAC). *Yields up to $80 \%$ were obtained in the presence of Cul as catalyst.
1.0 Hz) due to the proton of the triazole ring which couples with one of the $\mathrm{F}$ atoms of the fluorinated aryl moiety. Furthermore, upon formation of the triazole moiety, the aryl protons $o$ - to the $\mathrm{X}$ group are displaced downfield of about $0.3 \mathrm{ppm}$, while the $\mathrm{m}^{-}$ protons are shifted downfield of about $0.4 \mathrm{ppm}$. The ${ }^{13} \mathrm{C}$ NMR spectra are in keeping with the proposed structures (ESI $\dagger$ ).

The electronic absorption and emission spectra have been recorded at $298 \mathrm{~K}$ in $\mathrm{CHCl}_{3}$ solution; as an example, the UV spectrum of $2 \mathbf{c}$ is shown in Fig. 1. All the spectra show an absorption maximum at $290 \mathrm{~nm}$ indicating that the nature of the $\mathrm{X}$ atom does not affects significantly the optical activity. The corresponding emission spectra were obtained by excitation at the maximum absorbance frequency. All the excitation spectra display a maximum emission at $350 \mathrm{~nm}$ and result composed by a series of band and shoulders separated by about $1400 \mathrm{~cm}^{-1}$, probably corresponding to the vibrational structure of the ground state.

Single crystals of the push-pull molecule $2 \mathrm{c}$ have been obtained from chloroform solution, upon slow evaporation at room temperature. They were extremely thin plates, often curved and always twinned. One of the thickest crystal has been selected for single crystal X-ray analysis. Although it was twinned with large mosaicity, we were able to solve the structure with a good resolution, obtaining details about the supramolecular organization of the self-complementary molecules in the crystal lattices. CCDC no. 1453398, contains the supplementary crystallographic data for $\mathbf{2 c}$.

Compound $2 \mathrm{c}$ crystallizes in the monoclinic space group $P 2_{1} /$ $n$ with three independent molecules in the asymmetric unit. These three molecules, labelled as A, B and $\mathbf{C}$ in Fig. 2, differ essentially in the orientation of the two benzene rings with respect to the triazole ring. Looking at the N1-N2-C6-C5 and N3-C8-C9-C10 torsion angles in Fig. $2\left(-32.4(9)^{\circ}\right.$ and $22.9(9)^{\circ}$ for molecule A, 34.9(9) and $18.9(9)^{\circ}$ for $\mathbf{B}$ and $32.6(8)^{\circ}$ and $18.7(9)^{\circ}$ for $\left.\mathbf{C}\right)$, it appears that the benzene rings are anti-rotated in molecule $\mathbf{A}$, while they are syn-rotated in molecules $\mathbf{B}$ and $\mathbf{C}$. The main interaction in the crystal packing is the $\mathrm{I} \cdots \mathrm{N}$ halogen bond between the iodine atom on the tetrafluoro-benzene ring and the nitrogen atom of the dimethylamino group, which produces a significant pyramidalization of the latter. In fact

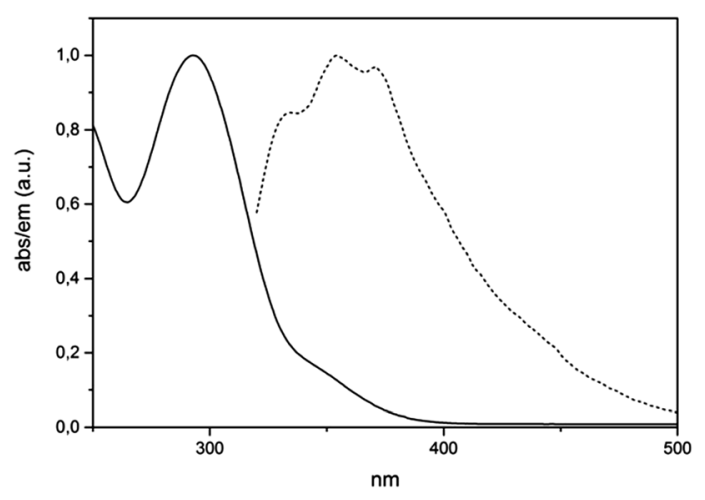

Fig. 1 Normalized UV-vis absorption (solid line) and fluorescence spectrum (dotted line) of $2 \mathrm{c}$ in $\mathrm{CHCl}_{3}\left(1 \times 10^{-6} \mathrm{M}\right)$. 

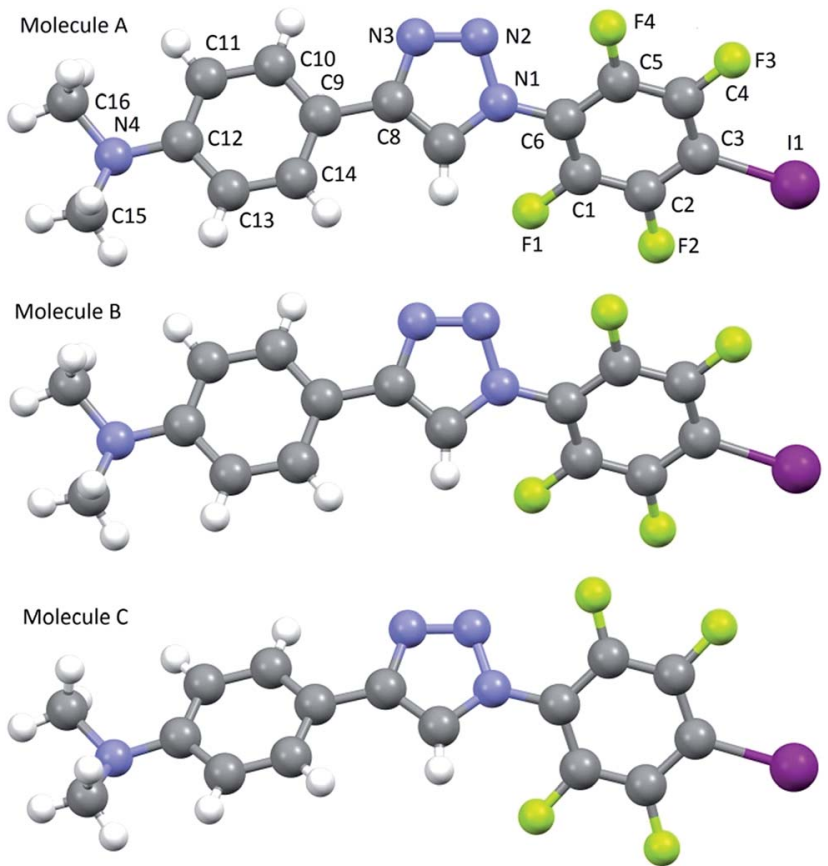

Fig. 2 The three independent molecules in the asymmetric unit of compound $2 \mathrm{c}$, showing the different conformation of $\mathrm{C}$ with respect to the similar A and B. The same labels have been assigned to chemically equivalent atoms. Colour code: $\mathrm{C}$, dark grey; $\mathrm{H}$, light grey; F, green; I, purple; N, blue.

a search for 4-dimethylaminophenyl groups in the CSD database (Version 5.36, November $2014+1$ update, with $R<0.005$, no disordered, no errors not polymeric, no ions, no powder structure, 572 hits, 836 data) revealed that the mean distance between $\mathrm{N}$ and the plane through its three bonded carbon atoms is 0.118(15) A with the upper quartile of $0.154 \AA$, while in 2c this distance is 0.298(7), 0.283(7) and 0.311(6) $\AA$, for A, B and C molecules, respectively.

The occurrence of halogen bond between these selfcomplementary molecules produces two different unlimited zig-zag chains, the first made of alternating $\mathbf{A}$ and $\mathbf{B}$ molecules $(\cdots \mathbf{A} \cdots \mathbf{B} \cdots \mathbf{A} \cdots \mathbf{B} \cdots)$, the second only of $\mathbf{C}$ molecules $(\cdots \mathbf{C} \cdots \mathbf{C} \cdots)$ (see Fig. 3). The halogen bonds in these zig-zag chains are similar: the $\mathrm{I} \cdots \mathrm{N}$ distance is $2.940(5), 2.906(5)$ and $2.942(2) \AA$ for the $\mathrm{I} 1 \mathrm{~A} \cdots \mathrm{N} 4 \mathrm{~B}$, I1B $\cdots \mathrm{N} 4 \mathrm{~A}$ and $\mathrm{I} 1 \mathrm{C} \cdots \mathrm{N} 4 \mathrm{C}$ bonds, respectively. The corresponding C3-I1 $\cdots \mathrm{N} 4$ angles are 170.0(2), 168.83(2) and $169.2(2)^{\circ}$ while the $\mathrm{I} 1 \cdots \mathrm{N} 4-\mathrm{C} 12$ are $96.9(4), 98.4(4)$ and $100.2(3)^{\circ}$. Parallel triplets of this chain, two of type $\cdots \mathrm{A} \cdots \mathrm{B} \cdots \mathrm{A} \cdots$ $\mathrm{B} \cdots$ and the third of type $\cdots \mathrm{C} \cdots \mathrm{C} \cdots$ are linked together only by weak $\mathrm{I} \cdots \mathrm{H}$ and $\mathrm{N} \cdots \mathrm{H}$ contacts, producing a sort of waved tape, clearly shown in Fig. 3. No other significant contact is present in the structure. The head-to-tail assembly of these selfcomplementary XB modules ensures that each chain is polar, although the coupling of antiparallel dipoles generates a centrosymmetric structure, as clearly indicated by the centric space group $\left(P 2_{1} / n\right)$, where adjacent chains adopt an antiparallel arrangement.

It is well established, both experimentally and theoretically, that the environment strongly influences NLO responses of

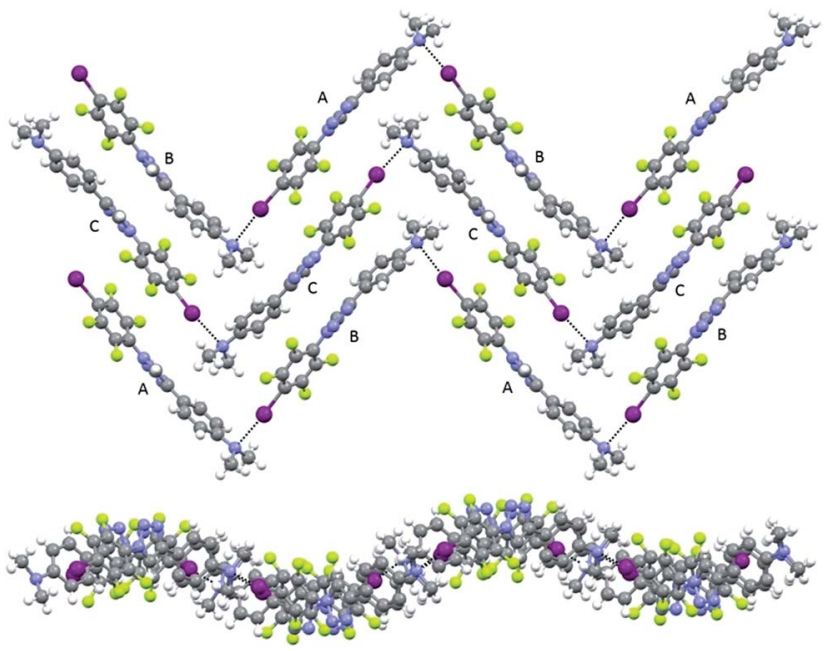

Fig. 3 Top: ball-and-stick view down the crystallographic a axis of three unlimited 1D halogen-bonded chains in 2c structure; the labels point out the positions of the three independent molecules. Bottom: the same chains projected along the $c$-axis, showing the their waving. Colours as follows: $C$, dark grey; $H$, light grey; $F$, green; I, purple; $N$, blue; XB, dotted black lines.

molecules. ${ }^{59,60}$ In fact, there are many examples of theoretical and experimental investigations describing that the formation of specific solute-solvent hydrogen bonding increases the value of $\beta$. Similarly, we have already demonstrated that the occurrence of $\mathrm{XB}$ influences the NLO properties of molecules in solution. ${ }^{61,62}$

Here we have extended our analysis to compound 2c whose second-order NLO properties were examined by the solutionphase electric field induced second-harmonic (EFISH) generation method. ${ }^{63,64}$ Measurements of $\mu \beta_{\lambda}$ (the product between the molecular dipole moment $\mu$ and the projection of the quadratic hyperpolarizability tensor $\beta_{\text {tot }}$ along $\mu$ ) were carried out in $\mathrm{CHCl}_{3}$ and DMF solutions, at $1907 \mathrm{~nm}$ non-resonant wavelength. Interestingly, in agreement with previous studies, ${ }^{61,62}$ an inversion, from positive to negative, of the sign of the $\mu \beta_{\lambda}$ is observed on going from $\mathrm{CHCl}_{3}\left(+58 \times 10^{-48} \mathrm{esu}\right)$ to $\mathrm{DMF}(-98$ $\times 10^{-48} \mathrm{esu}$ ) due to the involvement of the $\mathrm{I}$ atom of $2 \mathrm{c}$ in the formation of specific halogen-bonded adducts where the XB acceptor is DMF. Both the lower $\mu \beta_{\lambda}$ and absorption maximum of $2 \mathrm{c}$ with respect to our previously investigated system bearing the same donor and acceptor moieties but a double bond conjugated bridge $\left(\mu \beta_{\lambda}\right.$ equal to +124 and $-380 \times 10^{-48}$ esu in $\mathrm{CHCl}_{3}$ and DMF respectively; $\lambda_{\text {max }}$ equal to $382 \mathrm{~nm}$ ) indicate the triazole ring as a less efficient $\pi$ bridge.

\section{Conclusions}

In summary, we have described the synthesis of new heteroditopic self-complementary tectons designed in order to possess terminal halogen bond donor and acceptor groups connected by a 1,2,3-triazole ring as $\pi$-bridge. We found that 4 halo-tetrafluorobenzene-azides can be quite efficiently coupled with $\mathrm{N}, \mathrm{N}$-dimethylbenzenamine, despite the presence of EWS 
substituents on the aromatic ring, demonstrating the effectiveness of CuAAC "click chemistry" in the synthesis of a novel series of chromophores having A- $\pi-\mathrm{D}$ structure.

The crystal structure of the iodo-derivative $2 \mathrm{c}$ show that the presence of self-complementary XB-donor and acceptor groups drives their self-assembly into head-to-tail halogen-bonded infinite polar chains. However, such polar chains aggregate according to a centrosymmetric crystal structure giving macroscopically a null second-order NLO response in the solid state. EFISH measurements in chloroform and DMF solutions confirm that the NLO responses in solution can be tuned thanks to solvent $\cdots$ chromophore $\mathrm{XB}$ interactions, since an inversion, from positive to negative, of the sign of the $\mu \beta_{\lambda}$ is observed on going from $\mathrm{CHCl}_{3}$ to DMF.

Owing to the modular nature of the CuAAC reaction, it seems the new approach may be extended to the synthesis of other selfcomplementary molecular modules for halogen bonding driven self-assembly. Taking into account the effectiveness of XB in driving the formation of infinite polar chains, the synthetic approach described in this paper may be exploited for the synthesis of new organic chromophores showing high NLO activity in the solid state, provided a careful molecular design is applied in order to avoid the formation of centrosymmetric crystals.

\section{Acknowledgements}

The European Research Council (ERC) is gratefully acknowledged for funding the Starting Grant FOLDHALO (Grant Agreement Number 307108) to P. M.

\section{Notes and references}

1 P. Metrangolo, F. Meyer, T. Pilati, G. Resnati and G. Terraneo, Angew. Chem., Int. Ed., 2008, 47, 6114-6127.

2 F. Meyer and P. Dubois, CrystEngComm, 2013, 15, 3058-3071.

3 G. Cavallo, P. Metrangolo, R. Milani, T. Pilati, A. Priimagi, G. Resnati and G. Terraneo, Chem. Rev., 2016, 116, 24782601.

4 P. Metrangolo, G. Resnati, T. Pilati and S. Biella, Struct. Bonding, 2008, 126, 105-136.

5 C. B. Aakeröy, T. K. Wijethunga and J. Desper, J. Mol. Struct., 2014, 1072, 20-27.

6 S. Schindler and S. M. Huber, in Halogen Bonding II: Impact on material chemistry and life science, ed. P. Metrangolo and G. Resnati, Springer International Publishing, Cham, 2015, pp. 167-203.

7 M. Baldrighi, D. Bartesaghi, G. Cavallo, M. R. Chierotti, R. Gobetto, P. Metrangolo, T. Pilati, G. Resnati and G. Terraneo, CrystEngComm, 2014, 16, 5897-5904.

8 Y. Lu, Y. Liu, Z. Xu, H. Li, H. Liu and W. Zhu, Expert Opin. Drug Discovery, 2012, 7, 375-383.

9 S. Sirimulla, J. B. Bailey, R. Vegesna and M. Narayan, J. Chem. Inf. Model., 2013, 53, 2781-2791.

10 A. Bertolani, L. Pirrie, N. Houbenov, J. Haataja, L. Stefan, L. Catalano, G. Terraneo, G. Giancane, L. Valli, R. Milani,
O. Ikkala, G. Resnati and P. Metrangolo, Nat. Commun., 2015, 6, 1-9.

11 J. Mareda and S. Matile, Chemistry, 2009, 15, 28-37.

12 A. V. Jentzsch, D. Emery, J. Mareda, S. K. Nayak, P. Metrangolo, G. Resnati, N. Sakai and S. Matile, Nat. Commun., 2012, 3, 905.

13 N. H. Evans and P. D. Beer, Angew. Chem., Int. Ed., 2014, 53, 11716-11754.

14 J. M. Mercurio, A. Caballero, J. Cookson and P. D. Beer, RSC Adv., 2015, 5, 9298-9306.

15 F. Pan, N. K. Beyeh and K. Rissanen, $R S C A d v$., 2015, 5, 57912-57916.

16 G. Berger, J. Soubhye and F. Meyer, Polym. Chem., 2015, 6, 3559-3580.

17 A. Priimagi, G. Cavallo, P. Metrangolo and G. Resnati, Acc. Chem. Res., 2013, 46, 2686-2695.

18 M. Fourmigué, in Halogen bonding. Fundamentals and applications, ed. P. Metrangolo and G. Resnati, Springer, Berlin Heidelberg, 2008, vol. 126, pp. 181-207.

19 G. Resnati, P. Metrangolo, D. W. Bruce and G. Terraneo, in Abstracts of Papers, 234th ACS National Meeting, Boston, MA, United States, August 19-23, 2007, American Chemical Society, 2007, p. PHYS-151.

20 T. Shirman, R. Kaminker, D. Freeman and M. E. Van Der Boom, ACS Nano, 2011, 5, 6553-6563.

21 L. Meazza, J. A. Foster, K. Fucke, P. Metrangolo, G. Resnati and J. W. Steed, Nat. Chem., 2013, 5, 42-47.

22 S. Yasuda, A. Furuya and K. Murakoshi, RSC Adv., 2014, 4, 58567-58572.

23 T. Mukai and K. Nishikawa, RSC Adv., 2013, 3, 19952-19955.

24 G. R. Desiraju, P. S. Ho, L. Kloo, A. C. Legon, R. Marquardt, P. Metrangolo, P. Politzer, G. Resnati and K. Rissanen, Pure Appl. Chem., 2013, 85, 1711-1713.

25 P. Politzer, J. S. Murray and T. Clark, in Halogen Bonding I: Impact on Materials Chemistry and Life Science, ed. P. Metrangolo and G. Resnati, Springer International Publishing, 2015, pp. 19-42.

26 T. Clark, M. Hennemann, J. S. Murray and P. Politzer, J. Mol. Model., 2007, 13, 291-296.

27 K. E. Riley, J. S. Murray, J. Fanfrlík, J. Řezáč, R. J. Solá, M. C. Concha, F. M. Ramos and P. Politzer, J. Mol. Model., 2011, 17, 3309-3318.

28 R. Liantonio, P. Metrangolo, T. Pilati, G. Resnati and A. Stevenazzi, Cryst. Growth Des., 2003, 3, 799-803.

29 P. Metrangolo, F. Meyer, G. Resnati and M. Ursini, ACS Symp. Ser., 2005, 911, 514-542.

30 A. Abate, S. Biella, G. Cavallo, F. Meyer, H. Neukirch, P. Metrangolo, T. Pilati, G. Resnati and G. Terraneo, J. Fluorine Chem., 2009, 130, 1171-1177.

31 G. Cavallo, S. Biella, J. Lü, P. Metrangolo, T. Pilati, G. Resnati and G. Terraneo, J. Fluorine Chem., 2010, 131, 1165-1172.

32 P. Metrangolo, F. Meyer, T. Pilati, G. Resnati and G. Terraneo, Chem. Commun., 2008, 1635-1637.

33 C. Guardigli, R. Liantonio, M. L. Mele, P. Metrangolo, G. Resnati and T. Pilati, Supramol. Chem., 2003, 15, 177188. 
34 T. Caronna, R. Liantonio, T. a. Logothetis, P. Metrangolo, T. Pilati and G. Resnati, J. Am. Chem. Soc., 2004, 126, 45004501.

35 H. Amii and K. Uneyama, Chem. Rev., 2009, 109, 2119-2183.

36 P. Metrangolo, H. Neukirch, T. Pilati and G. Resnati, Acc. Chem. Res., 2005, 38, 386-395.

37 H. C. Kolb, M. G. Finn and K. B. Sharpless, Angew. Chem., Int. Ed., 2001, 40, 2004-2021.

38 C. W. Tornøe, C. Christensen and M. Meldal, J. Org. Chem., 2002, 67, 3057-3064.

39 V. V. Rostovtsev, L. G. Green, V. V. Fokin and K. B. Sharpless, Angew. Chem., Int. Ed., 2002, 41, 2596-2599.

40 A. A. Ali, M. Chetia, P. J. Saikia and D. Sarma, RSC Adv., 2014, 4, 64388-64392.

41 M. Malkoch, K. Schleicher, E. Drockenmuller, C. J. Hawker, T. P. Russell, P. Wu and V. V. Fokin, Macromolecules, 2005, 38, 3663-3678.

42 P. Wu, A. K. Feldman, A. K. Nugent, C. J. Hawker, A. Scheel, B. Voit, J. Pyun, J. M. J. Fréchet, K. B. Sharpless and V. V. Fokin, Angew. Chem., Int. Ed., 2004, 43, 3928-3932.

43 M. J. Joralemon, R. K. O'Reilly, J. B. Matson, A. K. Nugent, C. J. Hawker and K. L. Wooley, Macromolecules, 2005, 38, 5436-5443.

44 E. Fernandez-Megia, J. Correa, I. Rodríguez-Meizoso and R. Riguera, Macromolecules, 2006, 39, 2113-2120.

45 B. Helms, J. L. Mynar, C. J. Hawker and J. M. J. Fréchet, J. Am. Chem. Soc., 2004, 126, 15020-15021.

46 C. Ornelas, J. R. Aranzaes, L. Salmon and D. Astruc, Chem.Eur. J., 2008, 14, 50-64.

47 E. Moore, P.-Y. Wang, A. P. Vogt, C. T. Gibson, V. Haridas and N. H. Voelcker, RSC Adv., 2012, 2, 1289-1291.

48 S. S. Bag and R. Kundu, J. Org. Chem., 2011, 76, 3348-3356.
49 D. Schweinfurth, K. I. Hardcastle and U. H. F. Bunz, Chem. Commun., 2008, 2203.

50 J. Shi, L. Liu, J. He, X. Meng and Q. Guo, Chem. Lett., 2007, 36, 1142-1143.

51 T. Duan, K. Fan, Y. Fu, C. Zhong, X. Chen, T. Peng and J. Qin, Dyes Pigm., 2012, 94, 28-33.

52 A. S. Cornec, C. Baudequin, C. Fiol-Petit, N. Plé, G. Dupas and Y. Ramondenc, Eur. J. Org. Chem., 2013, 1908-1915.

53 M. Parent, O. Mongin, K. Kamada, C. Katan and M. Blanchard-Desce, Chem. Commun., 2005, 2029-2031.

54 M. J. Cho, D. H. Choi, P. A. Sullivan, A. J. P. Akelaitis and L. R. Dalton, Prog. Polym. Sci., 2008, 33, 1013-1058.

55 F. Bureš, RSC Adv., 2014, 4, 58826-58851.

56 M. Zhang, G. Deng, A. Zhang, H. Xu, H. Huang, C. Peng, S. Bo, X. Liu, Z. Zhen and L. Qiu, RSC Adv., 2014, 4, 33312.

57 C. Recsei and C. S. P. McErlean, Tetrahedron, 2012, 68, 464480.

58 L. Cao, C. Liu, X. Tang, X. Yin and B. Zhang, Tetrahedron Lett., 2014, 55, 5033-5037.

59 A. Abbotto, L. Beverina, S. Bradamante, A. Facchetti, C. Klein, G. A. Pagani, M. Redi-Abshiro and R. Wortmann, Chem.-Eur. J., 2003, 9, 1991-2007.

60 F. L. Huyskens, P. L. Huyskens and A. P. Persoons, J. Chem. Phys., 1998, 108, 8161-8171.

61 E. Cariati, G. Cavallo, A. Forni, G. Leem, P. Metrangolo, F. Meyer, T. Pilati, G. Resnati, S. Righetto, G. Terraneo and E. Tordin, Cryst. Growth Des., 2011, 11, 5642-5648.

62 E. Cariati, A. Forni, S. Biella, P. Metrangolo, F. Meyer, G. Resnati, S. Righetto, E. Tordin and R. Ugo, Chem. Commun., 2007, 2590.

63 B. F. Levine and C. G. Bethea, J. Chem. Phys., 1975, 73, 2666. 64 I. Ledoux and J. Zyss, Chem. Phys., 1982, 73, 203. 